CLINICAL STUDY

\title{
Diabetes caused by insulin gene (INS) deletion: clinical characteristics of homozygous and heterozygous individuals
}

\author{
Klemens Raile ${ }^{1,2}$, Michele O'Connell ${ }^{3}$, Angela Galler ${ }^{1}$, George Werther ${ }^{3}$, Peter Kühnen ${ }^{1}$, Heiko Krude ${ }^{1}$ \\ and Oliver Blankenstein ${ }^{1}$ \\ ${ }^{1}$ Department of Pediatric Endocrinology and Diabetes, Charité Children's Hospital, Universitätsmedizin Berlin, Charité Campus Virchow, Augustenburger \\ Platz 1, D-13353 Berlin, Germany, ${ }^{2}$ Experimental and Clinical Research Center, Max-Delbrück-Center, Berlin, Germany and ${ }^{3}$ The Royal Children's \\ Hospital and Murdoch Children's Research Institute, Melbourne, Victoria, Australia \\ (Correspondence should be addressed to K Raile at Department of Pediatric Endocrinology and Diabetes, Charité Children's Hospital, Universitätsmedizin \\ Berlin; Email: klemens.raile@charite.de)
}

\begin{abstract}
Background: Mutations of the preproinsulin gene (INS) account for both permanent neonatal diabetes (PND) and adult-onset diabetes. The molecular mechanism of complete INS deletion has recently been published and we now add clinical data of homozygous and heterozygous subjects as well as the detailed mapping of the $646 \mathrm{bp}$ deletion of the INS gene.

Methods: Location and size of the INS deletion was mapped in one case with PND and INS genotype of the whole family was further characterized by breakpoint-spanning PCR. The phenotype of monoallelic loss of INS was studied in 33 adult family members of a large consanguineous kindred with INS deletion.

Results: The 646 bp deletion was found in two individuals with PND that included exons 1 and 2 of the INS gene (chr11: g.2138434_2139080del646) and results in loss of approximately half of the preproinsulin protein. The two boys with homozygous INS deletion (D/D) presented with reduced birth weight, PND within the first $24 \mathrm{~h}$ of life and complete absence of C-peptide. Adult family members with the N/D had diabetes onset with earliest 25 years, while the oldest subject without diabetes was 45 years. INS-deletion-diabetes was initially treated with oral antidiabetic drugs but then transferred to insulin within 5-16 years. Overall, N/D-subjects $(n=11)$ had a higher risk to develop insulindependent diabetes up to the fifth decade, if compared with normal subjects $(n=22)$.

Conclusion: Complete loss of the human INS gene results in neonatal diabetes, while heterozygous INS deletion is a strong risk factor for developing insulin-dependent diabetes at adult age.
\end{abstract}

European Journal of Endocrinology 165 255-260

\section{Introduction}

Diabetes mellitus is characterized by high blood glucose concentrations accompanied by insulin deficiency or impaired insulin function. Genetic factors that play a role in development of diabetes are increasingly recognized and are now established in diagnostic algorithms of autoantibody-negative diabetes $(1,2)$. Despite this, most diabetes genes act in a polygenetic fashion and few diabetes forms are caused by alterations of single genes (1). Detection and detailed characterization of these gene defects have improved our understanding of human pancreas and islet development and function. Furthermore, variation or mutation of the same gene can cause monogenic diabetes but also contribute to individual risk of the very common, polygenic type 2 diabetes (3-7). Recent studies indicated that autosomal dominant insulin gene mutations can cause permanent neonatal diabetes (PND) but also autoantibody-negative diabetes that is classified then as type $1 \mathrm{~B}$ or maturity-onset diabetes of the young (MODY)-type diabetes (8-10). The molecular mechanism behind these cases with a MODY-like presentation was suggested to be defective trafficking of proinsulin and increased endoplasmic reticulum (ER) stress (11). Recessive mutations of the preproinsulin (INS) gene have also been identified as a novel cause of neonatal diabetes and were the commonest cause of isolated PND in the offspring of consanguineous parents (12). In humans, complete loss or inactivation of the two insulin alleles clearly leads to insulin-deficient diabetes from birth, as it has been reported previously from our cases (12). But whether allelic depletion of INS has any human phenotype at all, remains controversial since inactivation of three of four mouse INS alleles (Ins $1^{-/-} / \operatorname{Ins} 2^{-/+}$) does not lead to diabetes during mouse lifespan (13).

In this study, we report on a large, consanguineous kindred with the deletion of exons 1 and 2 of the INS gene. The two boys with biallelic INS deletion had been 
reported recently (12) and we now add mapping data of the 646 bp deletion resulting in loss of half of the preproinsulin protein and proximal parts of the insulin promoter. Furthermore, we report the phenotype of subjects with a heterozygous INS deletion and their risk of developing adult-onset and insulin-dependent diabetes.

\section{Patients and methods}

\section{Subjects}

The family studied originates from Lebanon and within this family two children with PND have been investigated for anomalies of known genes causing monogenic diabetes including GCK, HNF1A, HNF4A, HNF1B, $K C N J 11$, and $A B C C 8$ genes. As these showed normal sequences, the insulin gene was investigated and finally loss of the exons 1 and 2 of the INS gene has been identified as the underlying cause and was reported recently (12). Extended clinical follow-up studies on the two index patients with PND were performed at the referring Diabetes Centers. After the biallelic deletion was found in both cases with PND, first-degree relatives (siblings and parents) of one case agreed in clinical investigation including oral glucose tolerance test (OGTT) and HbA1c measurement. Furthermore, we report on a total of 33 adult family members that were available for clinical history, genetic testing, and at least one capillary $\mathrm{HbA} 1 \mathrm{c}$ at the time of investigation. Informed consent was obtained from all studied individuals and the study has been approved by the local ethics committee of the Charité. OGTT have been performed in five family members according to a standardized protocol including baseline and postglucose insulin and C-peptide measurements. Insulin and C-peptide was measured by chemiluminescence enzyme immunoassay (Immulite 2000, Siemens, Munich, Germany).

\section{Data and sample collection}

Family studies have been performed partially in Lebanon, including collection of clinical data, capillary HbA1c-samples, and blood spots on filter paper for genetic testing. Those were done by one adult family member who was specifically trained to interview subjects on concomitant diseases and medication as well as to perform capillary blood tests and store samples appropriately. Classification of diabetes became difficult as onset of insulin deficiency and diabetes symptoms developed slowly and showed some variation between subjects. We classified those subjects as having diabetes if first, diabetes diagnosis was made by a physician or secondly, if diabetes was yet undiagnosed and $\mathrm{HbA} 1 \mathrm{c}$ has been higher than the threshold of $6.1 \%$, indicating at least relevant impaired carbohydrate metabolism. By this, we tried to compare diabetes status of family members living in European countries and Lebanon. We assume that we missed no cases with diabetes that required treatment or had a relevant HbA1c elevation.

\section{Mutation screening}

Samples for genetic testing have been collected as EDTA blood in cases followed in Melbourne and Berlin. In cases from Lebanon, capillary blood was collected on filter paper (Protein Saver 903, Whatman, Dassel, Germany) and DNA was subsequently isolated (DNA IQ Casework Sample Kit for Maxwell 16, Promega Corporation) and analyzed. The human INS gene was amplified in three exon-specific segments by PCR.

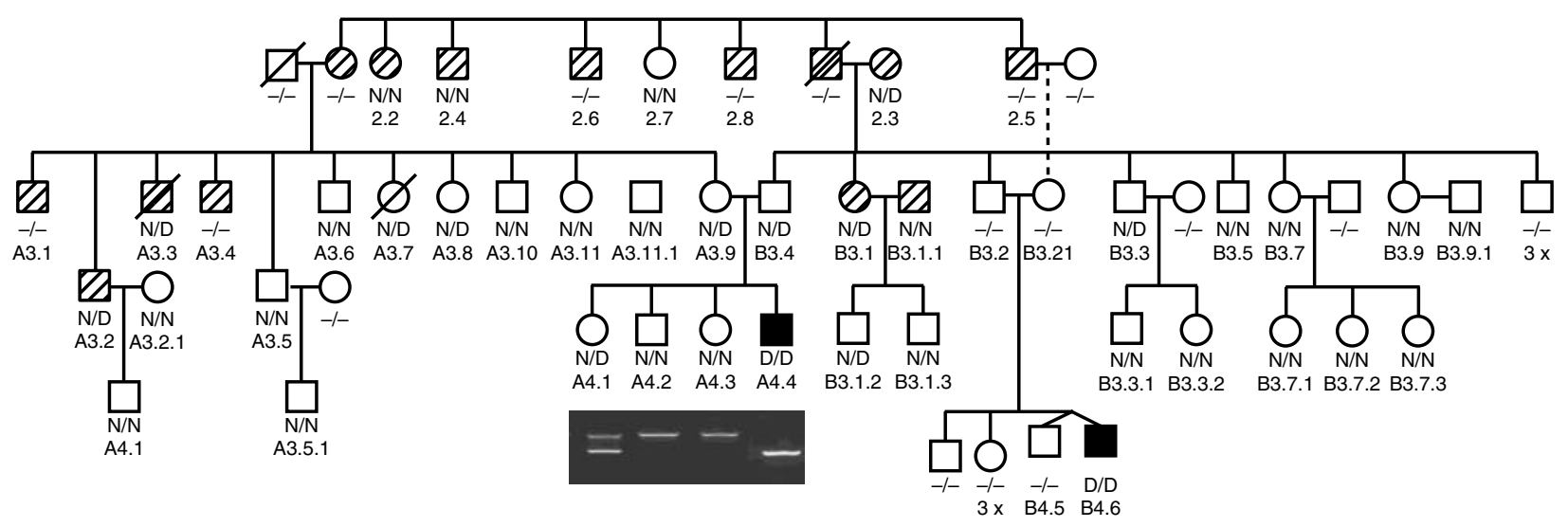

Figure 1 Pedigree of the family, genotype of tested subjects without deletion (N/N), with biallelic (D/D) or allelic (D/N) loss of INS are indicated. Filled symbols mark the two index cases with PND and hatched symbols those with adult-onset diabetes. The underage $(<18$ years) subjects A4.2, A4.3, A4.4, and B4.6 are indicated in this pedigree to give a complete picture of the index families but they are not included into statistical analyses reported in Table 1. The insert shows gel electrophoresis of PCR products using primers spanning the 646 bp breakpoint as an example from one patient with neonatal diabetes and his siblings (upper band $\sim 1000$ bp and lower band $\sim 350$ bp). 


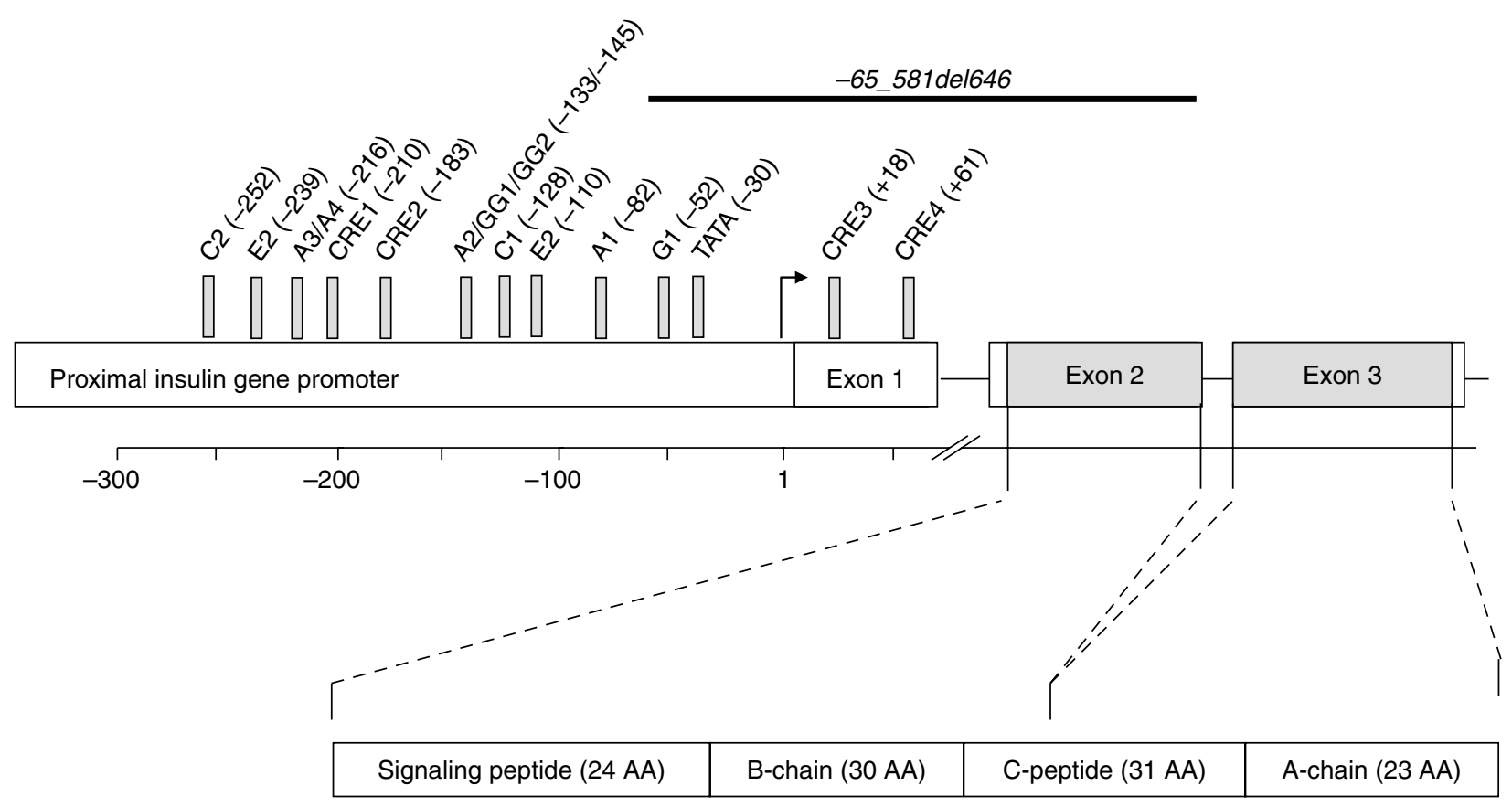

Figure 2 Schematic representation of the proximal INS gene showing the deletion above the gene. Transcription factor binding sites of the proximal promoter region are indicated at their respective position; a part of the preproinsulin protein that is coded by exon 2 and lost by the deletion is indicated below the nucleotide sequence. The nomenclature of the deletion is based on the coding sequence where nucleotide 1 represents translational start site.

We used the following primers: for the noncoding exon 1, forward $5^{\prime}$-ggcaggggttgagaggtag- $3^{\prime}$ and reverse $5^{\prime}$-aatcctgagccacctgac-3'; for exon 2 forward $5^{\prime}$-gaagcatgtgggggtgag- $3^{\prime}$ and reverse $5^{\prime}$-gctggtcactttaggacgtg- $3^{\prime}$; and for exon 3 forward $5^{\prime}$-ccctgactgtgtcctcctgt- $3^{\prime}$ and reverse $5^{\prime}$-agagagcgtggagagagctg- $3^{\prime}$. We used the Mastercycler ep gradient S Amplification System (Eppendorf AG, Hamburg, Germany). The PCR conditions were: $94{ }^{\circ} \mathrm{C} 5 \mathrm{~min}, 30$ cycles of $94{ }^{\circ} \mathrm{C}$ for $30 \mathrm{~s}, 59.5^{\circ} \mathrm{C}$ for $30 \mathrm{~s}$, and $72{ }^{\circ} \mathrm{C}$ for $30 \mathrm{~s} ; 72{ }^{\circ} \mathrm{C}$ for $10 \mathrm{~min}$ and $10^{\circ} \mathrm{C}$ for storage. Breakpoint-spanning PCR to discriminate between heterozygote deletion carriers was performed with the forward primer $5^{\prime}$-ccaggtcacccaggacttta- $3^{\prime}$ and the reverse primer 5'-gaggaagaggtgctgacgac-3'. PCR products were 977 or 331 bp for normal or INS deleted alleles respectively. The PCR amplification system and conditions were: Mastercycler ep gradient S Amplification System (Eppendorf AG) and $94{ }^{\circ} \mathrm{C} 5 \mathrm{~min}, 30$ cycles of $94{ }^{\circ} \mathrm{C}$ for $30 \mathrm{~s}, 58.8^{\circ} \mathrm{C}$ for $30 \mathrm{~s}$, and $72{ }^{\circ} \mathrm{C}$ for $2 \mathrm{~min} ; 72{ }^{\circ} \mathrm{C}$ for $10 \mathrm{~min}$ and $10^{\circ} \mathrm{C}$ for storage.

\section{Statistical analysis}

Clinical numeric data is given as median and range, where appropriate. Clinical characteristics of subjects were compared by Mann-Whitney $U$ or $\chi^{2}$ test (frequency of diabetes) by the statistical package PASW version 18 (Chicago, IL, USA).

\section{Results}

\section{Identification of insulin gene deletion in the family}

During the course of our studies of neonatal diabetes, we identified a consanguineous family (Fig. 1) in which diabetes at adult age appeared to segregate as a dominant trait, while neonatal diabetes occurred in a recessive way. Screening for INS mutation in these two cases resulted in a lack of the PCR product of the coding exon 2 and the noncoding exon 1, while exon 3 and the neighboring tyrosine hydroxylase gene $(T H)$ were well amplified (11). Thus, sequencing with several primer sets within the region between INS and TH was performed to characterize size and exact

Table 1 Clinical features of the 33 adult family members screened for the INS deletion.

\begin{tabular}{lll}
\hline & \multicolumn{2}{c}{ Genotype } \\
\cline { 2 - 3 } & $\mathrm{N} / \mathrm{D}$ & $\mathrm{N} / \mathrm{N}$ \\
\hline$n$ (male/female) & $11(6 / 5)$ & $22(10 / 12)$ \\
Diabetes/all & $5 / 11^{\mathrm{a}, \dagger}$ & $3 / 22^{\mathrm{a}}$ \\
Age (years) & $44.5(22-55)$ & $37.7(18-73.8)$ \\
Diabetes onset (years) & $44.0(25-47)^{\dagger}$ & $65(63-67)$ \\
BMl (kg/m $\left.{ }^{2}\right)$ & $23.1(19.9-32.7)$ & $25.1(16.0-38.5)$ \\
HbA1c $(\%)$ & $5.9(4.8-12.3)^{\star}$ & $5.2(4.3-6.9)$ \\
\hline
\end{tabular}

Values are median (minimum-maximum), significant differences: ${ }^{\star} P<0.05$, ${ }^{\dagger} P<0.01$ (N/N vs N/D with or without diabetes), ${ }^{a} \chi^{2}$ test. 
Table 2 Clinical characteristics and genotype of all eight subjects that developed diabetes.

\begin{tabular}{lllllll}
\hline & & & & & & Diabetes \\
\cline { 5 - 6 } Subject (sex) & $\begin{array}{l}\text { Present } \\
\text { age }(\mathrm{y})\end{array}$ & $\begin{array}{l}\text { Geno- } \\
\text { type }\end{array}$ & $\begin{array}{l}\text { Most } \\
\text { recent } \\
\text { HbA1c }(\%)\end{array}$ & $\begin{array}{l}\text { Most } \\
\text { recent BMI } \\
\left(\mathrm{kg} / \mathrm{m}^{2}\right)\end{array}$ & $\begin{array}{l}\text { Age at } \\
\text { onset }(\mathrm{y})\end{array}$ & Treatment \\
\hline A3.2 (male) & 54 & $\mathrm{D} / \mathrm{N}$ & 12.3 & 21.5 & 33 & $\begin{array}{c}\text { 33-34 y: diet; 34-49 y: OADs; } \\
\text { from 49 y: insulin }\end{array}$ \\
A3.3 (male) & 53 & $\mathrm{D} / \mathrm{N}$ & 12.2 & 20.2 & 40 & $40-49$ y: OADs; from 50 y: insulin \\
A3.4 (male) & 51 & $\mathrm{D} / \mathrm{N}$ & 6.5 & 26.2 & 42 & 42 y: OADs \\
A3.7 (female) & 44 & $\mathrm{D} / \mathrm{N}$ & 8.8 & 20.1 & 25 & 25-33 y: OADs; from 34 y: insulin \\
B3.1 (female) & 50 & $\mathrm{D} / \mathrm{N}$ & 6.9 & 27.8 & 47 & $47-50$ y: OAD \\
2.2 (female) & 74 & $\mathrm{~N} / \mathrm{N}$ & 6.7 & 32.3 & 65 & Diet no OADs \\
B3.1.1 (male) & 72 & $\mathrm{~N} / \mathrm{N}$ & 6.7 & 28.3 & 67 & Diet no OADs \\
2.4 (male) & 64 & $\mathrm{~N} / \mathrm{N}$ & 6.6 & 38.5 & 63 & Diet no OADs
\end{tabular}

OADs, oral antidiabetic drugs.

location of the deletion. We found a small deletion of $646 \mathrm{bp}$ including the proximal promoter region and exons 1 and 2 of the insulin gene (chr11: g.2138434_2139080del646). The deletion results in loss of all protein structures encoded by exon 2, namely signaling peptide, A-chain and half of C-peptide, but also of the proximal transcription factor binding sites G1, CRE3, CRE4, and the TATA box of the INS promoter (Fig. 2).

For family screening, a breakpoint-spanning PCR was established and we identified other subjects in the family with a heterozygous deletion of the INS exons 1 and 2 . Overall, 33 adult family members with complete clinical data and $\mathrm{HbAlc}$ were analyzed to calculate the diabetes risk associated with the N/D genotype, including 22 cases without deletion and 11 cases with the N/D genotype (Table 1 and Fig. 1).

\section{Patients with a homozygous INS gene deletion}

Neonatal diabetes in the two cases with complete INS deletion was diagnosed within the first hours of life and treated directly with insulin (Table 2). In keeping with severe insulin deficiency, both children also had significant intrauterine growth retardation and birth weight was markedly reduced (Table 3). Following insulin treatment, postnatal growth of both children was normal and caught up into growth percentiles of unaffected siblings. Apart from neonatal diabetes, neither boy had any other organ abnormality nor did both have impaired mental development.

\section{Subjects with a heterozygous INS gene deletion}

We tried to compare the diabetes status in family members living in Germany or in Lebanon respectively. The status 'diabetes' in this study was defined as diagnosis made by the physician (OGTT) or as HbAlc increased above $6.1 \%$ as the normal range cut off. This was largely applied to many family members from Lebanon, as they had not been regularly screened for diabetes. In the 33 adult family members that were available for genetic and clinical testing, diabetes was more frequent $(P<0.05)$ in those with N/D genotype (5 of 11) than with normal N/N (3 of 22) genotype (Table 1). Diabetic N/D-subjects had been diagnosed between 25 and 47 years of age and were initially treated with oral antidiabetic drugs (OADs). With a delay of 3-16 years, diabetes treatment was then changed to insulin in all cases with diabetes. Some cases with bad metabolic control also died of severe micro- and macro-vascular complications (subjects A

Table 3 Clinical and genetic characteristics of the two index families. Subjects presented are from Fig. 1.

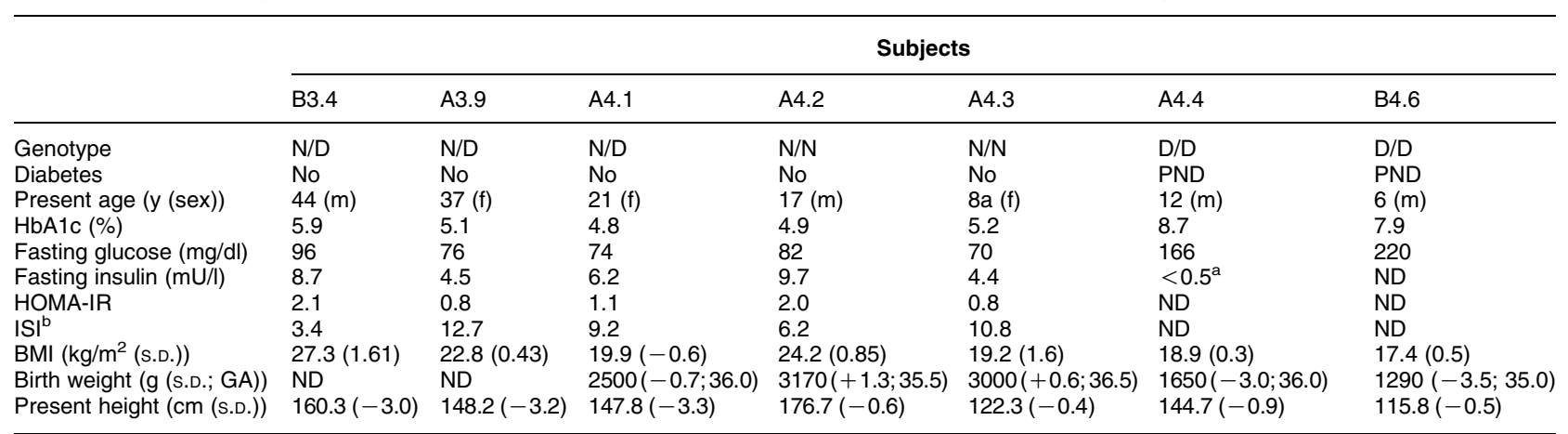

${ }^{\mathrm{a}} \mathrm{C}$-peptide, ND: not done, birth weights not known.

bInsulin sensitivity index published by Matsuda \& DeFronzo (20). 
3.3 and A 3.7). The three subjects with normal genotype and diabetes (Fig. 1, subjects B 3.1.1, 2.2, and 2.4) had mild symptoms at onset and were diagnosed approximately two decades later than N/Dsubjects (Tables 1 and 3).

Clinical investigation and OGTTs were performed in the index family with three members with N/D genotype and one index case with complete deletion (D/D; A4.4 in Fig. 1). The case with complete deletion (D/D) and neonatal diabetes from birth and displayed complete loss of C-peptide. On the contrary, the N/D-cases of the index family had no clinical signs of diabetes and displayed normal insulin sensitivity and insulin resistance as characterized by insulin sensitivity index (ISI) and HOMA-IR (Table 3).

As mentioned, birth weight was reduced in the D/D case as a result of reduced insulin secretion in utero, but whether heterozygous deletion carriers have a lower birth weight is not clear, as birth weights have not been documented in most adult family members born in Lebanon.

\section{Conclusions}

We report on a large family with subjects showing complete or heterozygous loss of the insulin gene. Complete loss results in neonatal diabetes, reduced birth weight and complete absence of C-peptide. Furthermore, heterozygous subjects have a relevant risk of developing insulin deficiency and diabetes with advanced age.

As reported recently, recessive INS mutations are a novel cause of permanent or transient neonatal diabetes (12). In humans, the phenotype of monoallelic loss of INS could be discussed controversial as in mice; a heterozygous null genotype at the Ins 2 locus is insufficient to cause diabetes, no matters whether alone or in combination with a homozygous null genotype at the Ins1 locus (13).

In humans, some heterozygous mutations of the INS gene are known to cause diabetes, if the resulting, mutant proinsulin is misfolded and thus leading to increased ER stress and finally a dominant-negative effect on pancreatic survival $\beta$-cell function (11). Diabetes in these patients with heterozygous INS mutations shows a broad spectrum of clinical phenotypes suggesting that different INS mutations behave differently. Comparing these patients and Ins1/Ins 2 ko animal observations (13) the hypothesis was stressed that in humans, only dominant-negative INS mutations are able to cause diabetes, while loss of one allele was suggested to be without clinical impact $(14,15)$. Given the recessive inheritance, heterozygous offspring are much more frequent; however, less is known about the clinical impact of monoallelic impairment of the INS gene.

The two boys with biallelic INS deletion had undetectable C-peptide levels and absent insulin function. Sequencing of the region between $T H$ and INS gene indicated a very small $646 \mathrm{bp}$ deletion that only affects parts of the insulin promoter, the noncoding exon 1 and the coding exon 2 of the INS gene. In detail, we have found that next to exons 1 and 2 basal promoter elements including the transcription factor binding sites G1, CRE3, CRE4, and the TATA box of the proximal INS promoter are lost. The basal $\sim 100 \mathrm{bp}$ promoter provides an assembly platform for the RNA polymerase II initiation complex and therefore next to exon 2, fundamental elements of regular INS transcription are also lost (16). CRE3 and CRE4 predominantly can interact with transcription factors activated by cAMP and diacylglycerol that can operate as activators, nonactivators, or suppressors (17). Mutagenesis experiments have shown that all four CRE sites of the human INS promoter are transcriptionally active (18). The human INS promoter G1 box (5'GTAGGGGA) binds the transcription factor Pur-1/MAZ and is specifically found in the primate INS promoter region (19).

Diabetes caused by heterozygous loss of one INS gene in our family was different from type 2 diabetes and characterized by normal or decreased body mass index (BMI) and early need of insulin treatment. Therefore, heterozygous subjects show characteristics of late-onset MODY-like or type 1B-like diabetes that resembles in some ways other monogenic diabetes forms that are associated with gene alterations of GCK, HNF1A, HNF1B, or HNF4A. This may suggest that sequencing and deletion analysis of INS should be included into diagnostic work up, if monogenic diabetes is assumed.

In summary, complete loss of the human INS gene results in neonatal diabetes, reduced birth weight and complete absence of C-peptide protein and insulin function. Furthermore, heterozygous INS deletion is a strong risk factor for developing diabetes at older age despite normal BMI. As heterozygous offspring might be frequent in a general population, genetic testing for INS gene alterations should be considered, if subjects are primarily insulin deficient and not obese.

\section{Declaration of interest}

The authors declare that there is no conflict of interest that could be perceived as prejudicing the impartiality of the research reported.

\section{Funding}

The research group of $\mathrm{K}$ Raile is funded by the Experimental and Clinical Research Center (ECRC), a center jointly established by the Charité Medical Faculty and the Max Delbrück Center for Molecular Medicine, Berlin, Germany. This research did not receive any specific grant from any commercial sector.

\section{Acknowledgements}

We are very grateful to all family members that participated in this study and made clinical and genetic studies possible. We thank Prof. Sian Ellard, Dr Emma Edghill, and Prof. Andrew Hattersley from the 
Peninsula Medical School, Exeter who carried out the initial genetic testing in some members of the family. Finally, we thank Dr Heike Biebermann and Sabine Jyrch for technical assistance.

\section{References}

1 Ellard S, Bellanne-Chantelot C \& Hattersley AT. Best practice guidelines for the molecular genetic diagnosis of maturity-onset diabetes of the young. Diabetologia 200851 546-553. (doi:10. 1007/s00125-008-0942-y)

2 Pearson ER, Starkey BJ, Powell RJ, Gribble FM, Clark PM \& Hattersley AT. Genetic cause of hyperglycaemia and response to treatment in diabetes. Lancet $2003 \mathbf{3 6 2}$ 1275-1281. (doi:10. 1016/S0140-6736(03)14571-0)

3 Omori S, Tanaka Y, Takahashi A, Hirose H, Kashiwagi A, Kaku K, Kawamori R, Nakamura Y \& Maeda S. Association of CDKAL1, IGF2BP2, CDKN2A/B, HHEX, SLC30A8, and KCNJ11 with susceptibility to type 2 diabetes in a Japanese population. Diabetes 200857 791-795. (doi:10.2337/db07-0979)

4 Cho YM, Kim TH, Lim S, Choi SH, Shin HD, Lee HK, Park KS \& Jang HC. Type 2 diabetes-associated genetic variants discovered in the recent genome-wide association studies are related to gestational diabetes mellitus in the Korean population. Diabetologia 200952 253-261. (doi:10.1007/s00125-008-1196-4)

5 Chistiakov DA, Potapov VA, Khodirev DC, Shamkhalova MS, Shestakova MV \& Nosikov VV. Genetic variations in the pancreatic ATP-sensitive potassium channel, beta-cell dysfunction, and susceptibility to type 2 diabetes. Acta Diabetologica $20094643-$ 49. (doi:10.1007/s00592-008-0056-5)

6 Bonnycastle LL, Willer CJ, Conneely KN, Jackson AU, Burrill CP, Watanabe RM, Chines PS, Narisu N, Scott LJ, Enloe ST, Swift AJ, Duren WL, Stringham HM, Erdos MR, Riebow NL, Buchanan TA, Valle TT, Tuomilehto J, Bergman RN, Mohlke KL, Boehnke M \& Collins FS. Common variants in maturity-onset diabetes of the young genes contribute to risk of type 2 diabetes in Finns. Diabetes 200655 2534-2540. (doi:10.2337/db06-0178)

7 Winckler W, Weedon MN, Graham RR, McCarroll SA, Purcell S, Almgren P, Tuomi T, Gaudet D, Bostrom KB, Walker M, Hitman G, Hattersley AT, McCarthy MI, Ardlie KG, Hirschhorn JN, Daly MJ, Frayling TM, Groop L \& Altshuler D. Evaluation of common variants in the six known maturity-onset diabetes of the young (MODY) genes for association with type 2 diabetes. Diabetes 2007 56 685-693. (doi:10.2337/db06-0202)

8 Polak M, Dechaume A, Cave H, Nimri R, Crosnier H, Sulmont V, de Kerdanet M, Scharfmann R, Lebenthal Y, Froguel P \& Vaxillaire M. Heterozygous missense mutations in the insulin gene are linked to permanent diabetes appearing in the neonatal period or in early infancy: a report from the French ND (Neonatal Diabetes) Study Group. Diabetes 200857 1115-1119. (doi:10.2337/db07-1358)

9 Stoy J, Edghill EL, Flanagan SE, Ye H, Paz VP, Pluzhnikov A, Below JE, Hayes MG, Cox NJ, Lipkind GM, Lipton RB, Greeley SA, Patch AM, Ellard S, Steiner DF, Hattersley AT, Philipson LH \& Bell GI. Insulin gene mutations as a cause of permanent neonatal diabetes. PNAS 2007104 15040-15044. (doi:10.1073/pnas. 0707291104 )

10 Molven A, Ringdal M, Nordbo AM, Raeder H, Stoy J, Lipkind GM, Steiner DF, Philipson LH, Bergmann I, Aarskog D, Undlien DE,
Joner G, Sovik O, Bell GI \& Njolstad PR. Mutations in the insulin gene can cause MODY and autoantibody-negative type 1 diabetes. Diabetes 200857 1131-1135. (doi:10.2337/db07-1467)

11 Meur G, Simon A, Harun N, Virally M, Dechaume A, Bonnefond A, Fetita S, Tarasov AI, Guillausseau PJ, Boesgaard TW, Pedersen O, Hansen T, Polak M, Gautier JF, Froguel P, Rutter GA \& Vaxillaire M. Insulin gene mutations resulting in early-onset diabetes: marked differences in clinical presentation, metabolic status, and pathogenic effect through endoplasmic reticulum retention. Diabetes 201059 653-661. (doi:10.2337/db09-1091)

12 Garin I, Edghill EL, Akerman I, Rubio-Cabezas O, Rica I, Locke JM, Maestro MA, Alshaikh A, Bundak R, Del Castillo G, Deeb A, Deiss D, Fernandez JM, Godbole K, Hussain K, O'Connell M, Klupa T, Kolouskova S, Mohsin F, Perlman K, Sumnik Z, Rial JM, Ugarte E, Vasanthi T, Johnstone K, Flanagan SE, Martinez R, Castano C, Patch AM, Fernandez-Rebollo E, Raile K, Morgan N, Harries LW, Castano L, Ellard S, Ferrer J, Perez de Nanclares G \& Hattersley AT. Recessive mutations in the INS gene result in neonatal diabetes through reduced insulin biosynthesis. PNAS 2010107 3105-3110. (doi:10.1073/pnas.0910533107)

13 Leroux L, Desbois P, Lamotte L, Duvillie B, Cordonnier N, Jackerott M, Jami J, Bucchini D \& Joshi RL. Compensatory responses in mice carrying a null mutation for Ins1 or Ins2. Diabetes 200150 (Suppl 1) S150-S153. (doi:10.2337/diabetes. 50.2007.S150)

14 Liu M, Haataja L, Wright J, Wickramasinghe NP, Hua QX, Phillips NF, Barbetti F, Weiss MA \& Arvan P. Mutant INS-gene induced diabetes of youth: proinsulin cysteine residues impose dominant-negative inhibition on wild-type proinsulin transport. PLOS ONE $2010 \quad 5$ e13333. (doi:10.1371/journal.pone. 0013333)

15 Liu M, Hodish I, Haataja L, Lara-Lemus R, Rajpal G, Wright J \& Arvan P. Proinsulin misfolding and diabetes: mutant INS geneinduced diabetes of youth. Trends in Endocrinology and Metabolism 201021 652-659. (doi:10.1016/j.tem.2009.11.004)

16 Andrali SS, Sampley ML, Vanderford NL \& Ozcan S. Glucose regulation of insulin gene expression in pancreatic beta-cells. Biochemical Journal 2008415 1-10. (doi:10.1042/BJ20081029)

17 Skoglund G, Hussain MA \& Holz GG. Glucagon-like peptide 1 stimulates insulin gene promoter activity by protein kinase A-independent activation of the rat insulin I gene cAMP response element. Diabetes 200049 1156-1164. (doi:10.2337/diabetes. 49.7.1156)

18 Hay CW \& Docherty K. Comparative analysis of insulin gene promoters: implications for diabetes research. Diabetes $2006 \mathbf{5 5}$ 3201-3213. (doi:10.2337/db06-0788)

19 Lew A, Rutter WJ \& Kennedy GC. Unusual DNA structure of the diabetes susceptibility locus IDDM2 and its effect on transcription by the insulin promoter factor Pur-1/MAZ. PNAS 200097 12508-12512. (doi:10.1073/pnas.97.23.12508)

20 Matsuda M \& DeFronzo RA. Insulin sensitivity indices obtained from oral glucose tolerance testing: comparison with the euglycemic insulin clamp. Diabetes Care 199922 1462-1470. (doi:10.2337/diacare.22.9.1462)

Received 1 May 2011

Accepted 12 May 2011 